\title{
A Seated Single-Person Dial-Test for Posterolateral Corner and Posterior Cruciate Ligament Knee Injuries
}

\author{
Jibu John Joseph, Jonathan Dearing \\ Ayr Hospital, Ayr, UK \\ Email: jibujohnjoseph@gmail.com
}

Received 19 October 2013; revised 19 November 2013; accepted 28 November 2013

Copyright (C 2014 by authors and Scientific Research Publishing Inc.

This work is licensed under the Creative Commons Attribution International License (CC BY). http://creativecommons.org/licenses/by/4.0/

\begin{abstract}
Background: Injuries to the posterolateral corner of the knee (PLC) can be difficult to diagnose and are often missed. The prone dial test can be difficult to perform in the acute setting and the supine dial test requires an assistant. Purpose: We present a simple single person seated dial test that can easily be performed in all patients with a suspected diagnosis of PLC injury. Study Design: Case Series. Method: The patient is seated on the edge of the examination couch with their knees flexed over the side and their calves pressed against the couch to reduce any posterior tibial subluxation. The patients' knees are placed together ensuring the pelvis is square; the knees are at the same level, and the patellae are facing anteriorly. The patients place their hands against the side of their knees and hold their knees together in this position. The examiner then grasps the patient's feet, approximates the medial malleoli and exerts a lateral rotational force at 30 and 90 degrees of knee flexion. Results: This test has $100 \%$ accuracy for diagnosing PLC injury in our institution. Conclusion: We present a sample to use alternative to traditional dial testing that does not require an assistant and also does not require the patient to be prone, thus limiting discomfort in the acute setting.
\end{abstract}

\section{Keywords}

Posterolateral Corner; Knee; Instability; Knee Examination

\section{Introduction}

Injuries to the posterolateral corner of the knee (PLC) are often difficult to diagnose and so are often missed [1]-[3]. This can result in significant disability secondary to persistent instability and pain.

How to cite this paper: Joseph, J.J. and Dearing, J. (2014) A Seated Single-Person Dial-Test for Posterolateral Corner and Posterior Cruciate Ligament Knee Injuries. Open Journal of Clinical Diagnostics, 4, 17-21. 
In PLC injury, the salient finding is that of increased tibial external rotation. This forms the basis for several clinical tests, most of which have fallen out of favour due to difficulty with interpretation and side-to-side comparison. Currently the dial testis most commonly used as this allows visual and tactile side-to-side comparison with the thigh-foot angle (TFA) or the patella-tubercle angle (PTA). The test can be done supine [4] or prone. Bae et al. have shown that the dial test correlates well with the degree of PLC injury [1] but it too can be difficult to perform accurately in a clinical setting [5]; the prone technique may be difficult for patients with painful swollen knees, and itis difficult to visualise the PTA at 30 degrees of flexion [6], and the standard supine technique requires an assistant to hold the thighs together [6].

Therefore, a simple, reliable and reproducible test needs to be used by a single clinician to identify disruption of the posterolateral corner. We present a single-person, seated technique that can be performed as a user-friendly alternative to traditional tests.

\section{Method}

The patient is seated on the edge of the examination couch with their knees flexed over the side and their calves pressed against the couch to reduce any posterior tibial subluxation (Figures 1 and 2). The patients' knees are placed together ensuring the pelvis is square, the knees are at the same level, and the patellae are facing anteriorly. The patient places their hands against the side of their knees and holds their knees together in this position (Figures 1 and 2). The examiner then grasps the patient's feet, approximates the medial malleoli and exerts a lateral rotational force at 30 and 90 degrees of knee flexion (Figures 1-3).

\section{Results}

Between October 2009 and October 2012 this test has been used to identify 42 patients with PLC knee injury. MRI scan confirmed the presence of a PLC injury in all patients. All patients proceeded to PLC reconstruction

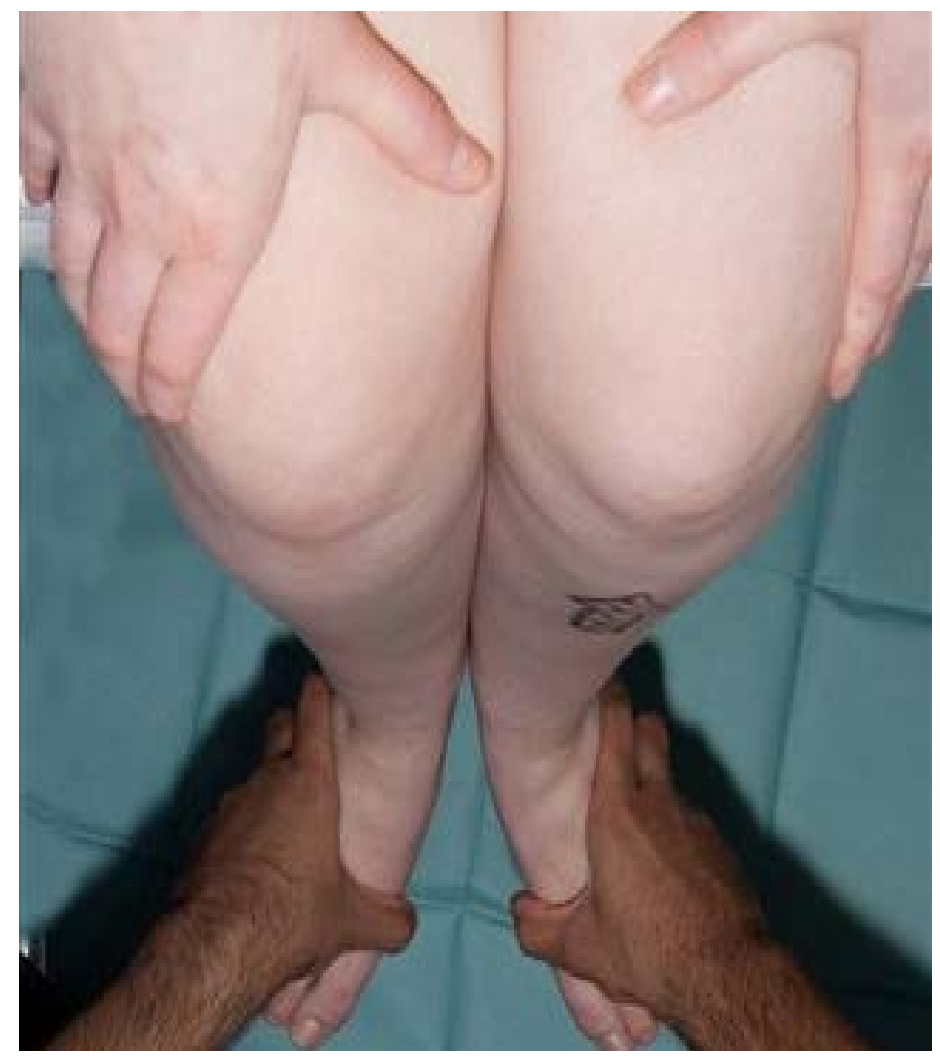

Figure 1. Clinical Photograph demonstrating patient holding knees togetherat 90 degrees of knee flexion with external rotation moment applied demonstrating equal rotation. 


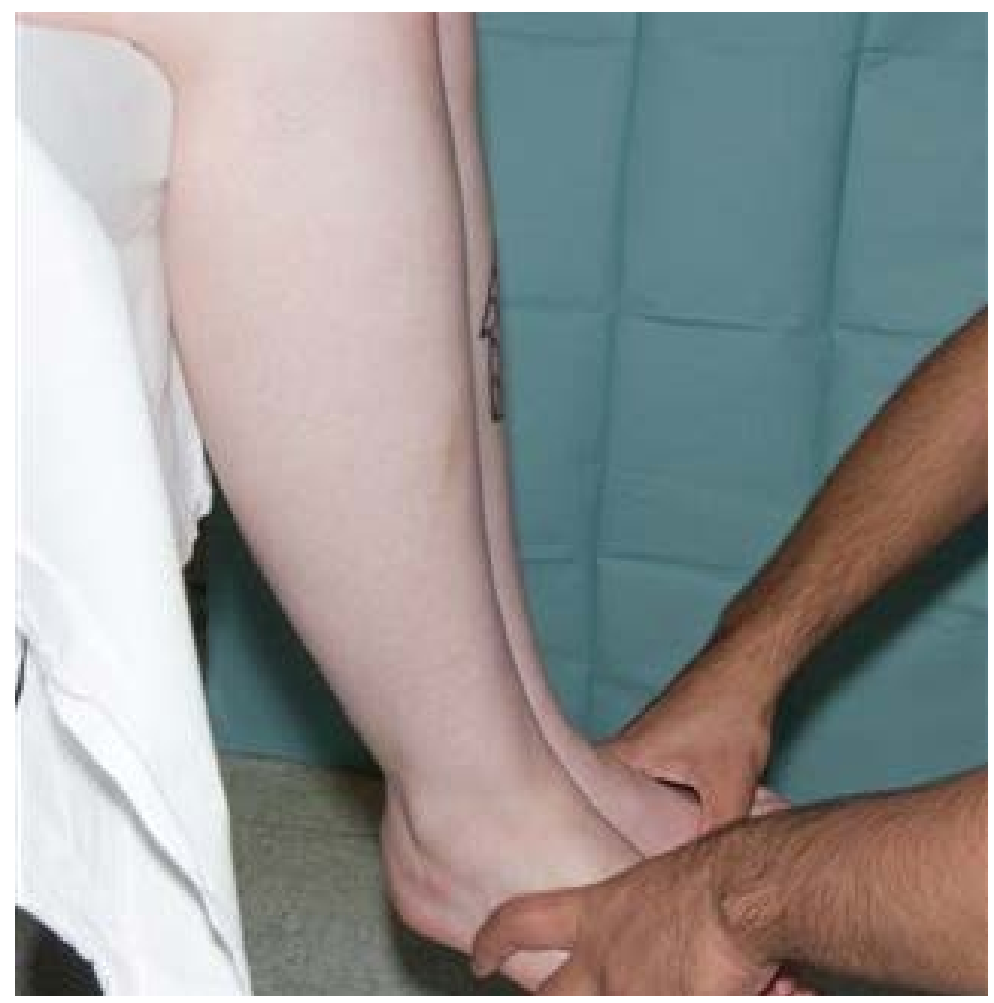

Figure 2. Clinical photograph demonstrating posterior aspect of tibiae pressed against examination couch at 90 degrees of flexion.

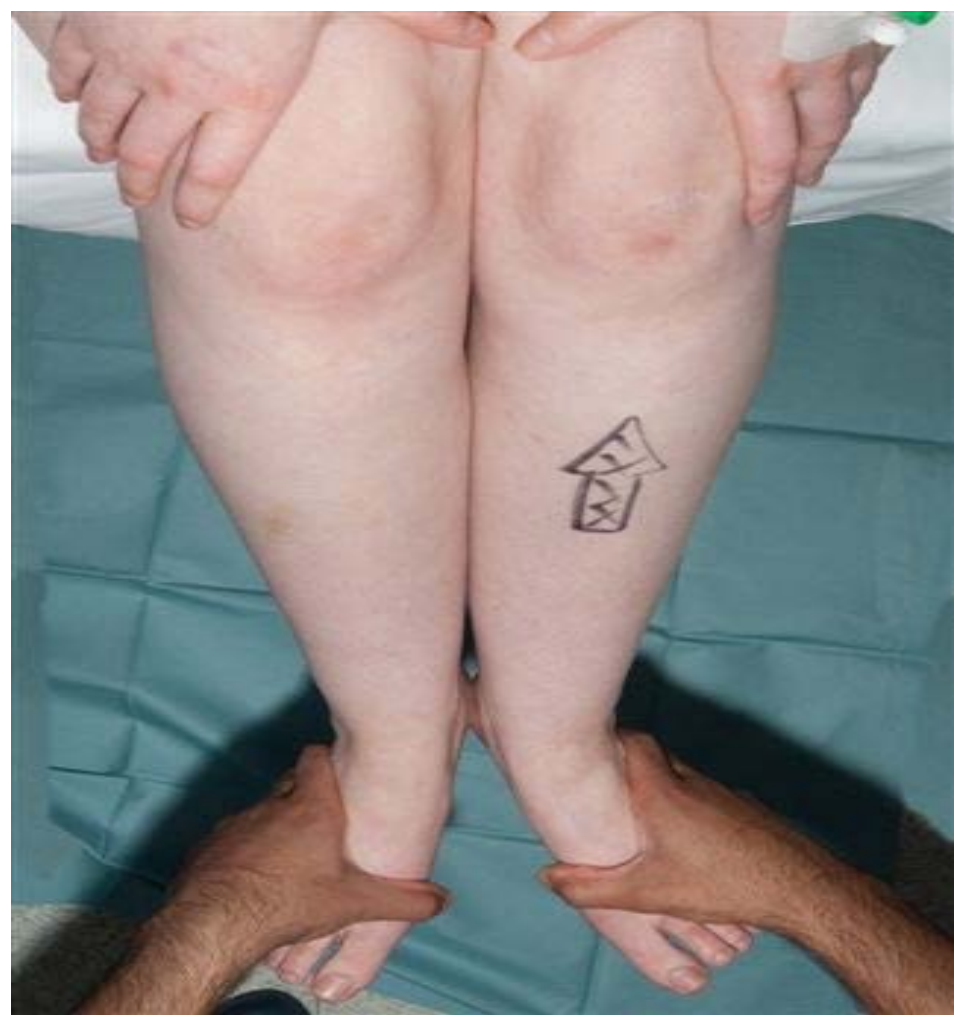

Figure 3. Clinical photograph demonstrating increased external rotation on the left at 30 degrees of knee flexion. 
and at the time of operation underwent traditional 2-person supine dial test evaluation under anaesthesia as well as arthroscopy to assess for a "drive through" sign. A positive traditional supine dial test and drive through sign was identified in all patients. In our institution, we have found $100 \%$ accuracy for the diagnosis of PLC injury with this test.

\section{Discussion}

Injuries to the posterolateral corner may be diagnosed using a number of clinical tests, such as the External rotation recurvatum [7], Posterolateral drawer [7] Reverse pivot shift [8], and Spin tests [9]. Many of these tests are inherently difficult to perform or interpret and issues regarding diagnostic accuracy in isolated PLC injury have been raised [6]. Hughstons' external rotation recurvatum test, for example, is only positive in combined cruciate ligament and PLC injury [10]. A posterolateral drawer test is difficult to quantify and as it is performed at 90 degrees of flexion will only be positive in combined PLC and PCL injury [11] [12]. Similarly the reverse pivot shift test relies on subluxation of the tibia at 90 degrees of flexion and will therefore only be positive in combined PLC and PCL injuries [6] [13].

With the supine dial test, Strauss et al. [14] showed increased external rotation when the test is performed with the tibiae anteriorly reduced. Jung et al. [5] [15] tested this hypothesis in a clinical setting and also found an increase in external rotation translating into improved sensitivity of the test. In the seated test that we have described the patients' calves are pressed against the couch thereby reducing any posterior subluxation.

When performing the supine technique an assistant is also required to hold the patients' knees together in order to avoid any femoral rotation and also to allow side-to-side comparison. In our test the patient is sitting and therefore can hold their knees together themselves obviating the need for an assistant. Also, in the sitting position with the medial malleoli held together by the examiner, any difference in femoral version is negated thus reducing the risk of false positive or negative results.

In the Spin test the examiner's hand is placed over the tibial tuberosity and the thumb is used to feel for rotation of the tibia in relation to the lateral femoral condyle. This test therefore relies on a tactile sensation of tibial rotation that is difficult to quantify and may be difficult to elicit in a large or painful, swollen knee. There is also no visual reference for side-to-side comparison as the tibial tuberosity is covered by the examiner's hands and the ankle has not been secured. Finally this test can only be performed at 90 degrees and therefore only applies in combined PLC and PCL injuries and can miss isolated PLC injuries.

\section{Conclusion}

Traditional tests for posterolateral corner injury can be difficult to both perform and interpret in an outpatient setting. The modified, seated dial test that we present is easily and reproducibly performed and interpreted in the outpatient setting without the need for an assistant.

\section{References}

[1] Bae, J.H., Choi, I.C., Suh, S.W., Lim, H.C., Bae, T.S., Nha, K.W. and Wang, J.H. (2008) Evaluation of the Reliability of the Dial Test for Posterolateral Rotatory Instability: A Cadaveric Study Using an Isotonic Rotation Machine. Arthroscopy: The Journal of Arthroscopic and Related Surgery, 24, 593-598. http://dx.doi.org/10.1016/j.arthro.2007.12.003

[2] Hughston, J.C. and Jacobson, K.E. (1985) Chronic Posterolateral Rotatory Instability of the Knee. The Journal of Bone \& Joint Surgery. American Volume, 67, 351-359.

[3] Veltri, D.M. and Warren, R.F. (1995) Posterolateral Instability of the Knee. Instructional Course Lectures, 44, 441453.

[4] Loomer, R.L. (1991) A Test for Knee Posterolateral Rotatory Instability. Clinical Orthopaedic Related Research, 264, 235-238.

[5] Jung, Y.B., Lee, Y.S., Jung, H.J. and Nam, C.H. (2009) Evaluation of Posterolateral Rotatory Knee Instability Using the Dial Test According to Tibial Positioning. Arthroscopy: The Journal of Arthroscopic and Related Surgery, 25, 257-261. http://dx.doi.org/10.1016/j.arthro.2008.10.007

[6] Alam, M., Bull, A.M.J., de Thomas, W.R. and Amis, A.A. (2011) Measurement of Rotational Laxity of the Knee. In Vitro Comparison of Accuracy between the Tibia, Overlying Skin, and Foot. The American Journal of Sports Medicine, 39, 2575-2581. http://dx.doi.org/10.1177/0363546511424872 
[7] Hughston, J.C. and Norwood Jr., L.A. (1980) The Posterolateral Drawer Test and External Rotational Recurvatum Test for Posterolateral Instability of the Knee. ClinOrthop, 147, 82-87.

[8] Jakob, R.P., Hassler, H. and Staeubli, H.U. (1981) Observations on Rotatory Instability of the Lateral Compartment of the Knee. Experimental Studies on the Functional Anatomy and the Pathomechanism of the True and the Reversed Pivot Shift Sign. Acta Orthopaedica Scandinavica. Supplementum, 191, 1-32.

[9] Marx, R.G., Shindle, M.K. and Warren, R.F. (2009) Management of Posterior Cruciate Ligament Injury. Operative Techniques in Sports Medicine, 17, 162-166.

[10] DeLee, J.C., Rile, M.B. and Rockwood Jr., C.A. (1983) Acute Posterolateral Rotatory Instability of the Knee. The American Journal of Sports Medicine, 11, 199-207. http://dx.doi.org/10.1177/036354658301100403

[11] Gollehon, D.L., Torzilli, P.A. and Warren, R.F. (1987) The Role of the Posterolateral and Cruciate Ligaments in the Stability of the Human Knee: A Biomechanical Study. The Journal of Bone \& Joint Surgery. American Volume, 69, 233-242.

[12] Grood, E.S., Stowers, S.F. and Noyes, F.R. (1988) Limits of Movement in the Human Knee: Effect of Sectioning the Posterior Cruciate Ligament and Posterolateral Structures. The Journal of Bone \& Joint Surgery. American Volume, 70, 88-97.

[13] Shelbourne, K.D., Benedict, F., McCarrol, J.R. and Retting, A.C. (1989) Dynamic Posterior Shift: An Adjuvant in Evaluation of Posterior Tibial Subluxation. The American Journal of Sports Medicine, 17, 275-277. http://dx.doi.org/10.1177/036354658901700221

[14] Strauss, E.J., Ishak, C., Inzerillo, C., Walsh, M., Yildirim, G., Walker, P., Jazrawi, L. and Rosen, J. (2007) Effect of Tibial Positioning on the Diagnosis of Posterolateral Rotatory Instability in the Posterior Cruciate Ligament-Deficient Knee. British Journal of Sports Medicine, 41, 481-485. http://dx.doi.org/10.1136/bjsm.2006.030767

[15] Jung, Y.B., Nam, C.H., Jung, H.J., Lee, Y.S. and Ko, Y.B. (2009) The Influence of Tibial Positioning on the Diagnostic Accuracy of Combined Posterior Cruciate Ligament and Posterolateral Rotatory Instability of the Knee. Clinics OrthopSurg, 68-73. 